\title{
Influence of random urine albumin-creatinine ratio of pregnant women with hypertension during the gestation period on perinatal outcome
}

\author{
QIAN YAN ${ }^{1}$, HONGMEI WANG ${ }^{2}$, RONGHUI LIU $^{1}$, LING JIANG $^{1}$, \\ JINGYING LIU ${ }^{1}$, LIJUAN WANG ${ }^{3}$ and YUANYING GUO ${ }^{4}$ \\ ${ }^{1}$ Department of Obstetrics and Gynecology, Yantaishan Hospital, Yantai, Shandong 264001; \\ ${ }^{2}$ Department of Obstetrics and Gynecology, Shandong Provincial Hospital, Jinan, Shandong 250021; \\ ${ }^{3}$ Department of Obstetrics and Gynecology, Zhaoyuan People's Hospital, Zhaoyuan, Shandong 265400; \\ ${ }^{4}$ School of Public Health, Jilin University, Changchun, Jilin 130021, P.R. China
}

Received May 20, 2016; Accepted August 19, 2016

DOI: $10.3892 / \mathrm{etm} .2016 .3620$

\begin{abstract}
The aim of the present study was to investigate the influence of the random urine albumin-creatinine ratio (ACR) of pregnant women with hypertension during the gestation period on perinatal outcome. A total of 6,758 pregnant women with pregnancy-induced hypertension and proteinuria were randomly selected between September, 2009 and June, 2015 for the study. Kidney function, blood pressure, history of gravidity and parity, embryo number and the birth weight of the participants was determined. Logistic regression and paired data correlation analyses were carried out with kidney function, blood pressure, history of gravidity and parity, embryo number, birth weight, maternal age, labor presentation and other risk factors as the independent variables and the newborn APGAR score as the dependent variable. The results showed that random urine ACR was increased and negatively correlated with the APGAR score $(\mathrm{OR}=-0.095, \mathrm{P}=0.017)$. In conclusion, the increased random urine ACR can influence the postpartum outcome. Early intervention of women of childbearing age in early pregnancy or before pregnancy can minimize the adverse complications of infants and mothers such as pregnancy hypertension syndrome, and improve the outcome of the pregnancy.
\end{abstract}

\section{Introduction}

The kidney undergoes a number of changes in internal structure and function during pregnancy. During normal pregnancy, the placenta and mother produce large amounts of hormones

Correspondence to: Dr Qian Yan, Department of Obstetrics and Gynecology, Yantaishan Hospital, 91 Jiefang Road, Yantai, Shandong 264001, P.R. China

E-mail: yan_qian111@163.com

Key words: pregnancy, hypertension, urinary albumin-creatinine ratio, logistic regression analysis including human chorionic gonadotropin (HCG), human placental lactogen (h-PL), steroid hormones and estrogen (1). Such changes in hormone levels can lead to changes in angiotasis and increase water-sodium retention and the volume load, resulting in changes of maternal hemodynamics and kidney structure and function (2-6). During normal pregnancy, 24-h urine protein and urinary albumin excretion increase significantly after 20 weeks to $200-300 \mathrm{mg}$ and $12-19 \mathrm{mg}$, respectively. The maximum urinary protein content can reach $500 \mathrm{mg} / 24 \mathrm{~h}(7,8)$.

The random urine albumin-creatinine ratio (ACR) is a reliable method for determining the urine protein-creatinine ratio and monitoring urinary protein excretion. The determination of the urine protein-creatinine ratio can effectively reflect the 24-h urine protein content of pregnant women. It is fast, simple, accurate and has other positive aspects that make it an ideal clinical indicator for the qualitative and quantitative diagnosis of proteinuria and for follow-up. It can replace the traditional $24-\mathrm{h}$ urine protein excretion quantification method (5). Clinically, proteinuria is often determined with 24-h urine protein, and normal urinary protein content is generally less than $0.15 \mathrm{~g} / 24 \mathrm{~h}$. However, this method is associated with difficulties such as being greatly influenced by maternal compliance. This is because of the longer urine sample collection time, especially when colleting 24-h urine sample from patients with young children. Therefore, the urine protein-creatinine ratio can be determined immediately to predict the $24 \mathrm{~h}$ urine protein content (9).

In the present study, random urine ACR was incorporated into evaluation and the perinatal outcomes of women were tracked and observed. Various risk factors affecting gestational hypertension and proteinuria were comprehensively analyzed to identify the risk factors of proteinuria of pregnant women with hypertension.

\section{Patients and methods}

Inclusion and exclusion criteria. The inclusion criteria of the study were: i) Women of childbearing age, $>18$; and ii) those 
Table I. APGAR score criteria.

Score criteria

\begin{tabular}{lccc}
\cline { 2 - 4 } Physical sign & 0 & 1 & 2 \\
\hline Skin color & Purple or pale & $\begin{array}{c}\text { The body was purplish red and } \\
\text { the limbs were blue and purple }\end{array}$ & The whole body was red \\
$\begin{array}{l}\text { Heart rate (beats/min) } \\
\text { Reaction of flicking planta } \\
\text { pedis or inserting nasal tube }\end{array}$ & None & $<100$ & $>100$ \\
$\begin{array}{l}\text { Muscle tension } \\
\text { Breathing }\end{array}$ & Loose & Some actions were made (such as frowning) & Cried and sneezed \\
& None & Limbs were slightly buckled & The limbs moved freely \\
Normal, cried loudly
\end{tabular}

with proteinuria during pregnancy. The exclusion criteria for the study were: i) Diabetes before pregnancy and previous history of hypertension; ii) pregnant women with lung infection, urinary system infection or other infections, cancers of the reproductive system or breast cancer; iii) heart, liver, kidney, lung and other organ failure; iv) dying from any diseases; v) abnormal blood clotting mechanism; vi) pregnant women or their families who could not provide cooperation; vii) history of mental illness; viii) not reaching the expected date of confinement or those whose families required terminating the pregnancy.

Clinical data. A total of 6,758 pregnant women with pregnancy-induced hypertension and proteinuria were randomly selected in the Yantai region from September, 2009 to June, 2011. The average age of participants was $25.3 \pm 12.6$ years, with mean arterial pressure of $118.5 \pm 21.3 \mathrm{mmHg}$ and $24-\mathrm{h}$ urine protein content of $121.7 \pm 14.5 \mathrm{mg}$.

Data collection. An experienced gynecologist collected the detailed medical history, conducted the physical examination on the participants and recorded their age, gender, height, weight, body mass index (BMI), blood triglyceride, blood low-density lipoprotein cholesterol, blood high-density lipoprotein cholesterol, serum insulin, fasting blood glucose, glycated hemoglobin, aspartate transaminase, $\gamma$-glutamyl transpeptidase, creatinine, history of hypertension and history of diabetes.

Diagnostic criteria. The diagnostic criteria were as follows (5): According to the 1999 WHO diagnostic criteria, $\geq 2$ measurements were carried out where systolic blood pressure $>140 \mathrm{mmHg}$ or diastolic blood pressure $>90 \mathrm{mmHg}$, or antihypertensive medications were being taken.

According to the 1999 WHO-IDF standards published, $\geq 2$ random measurements were carried out where blood glucose $>11.1 \mathrm{mmol} / 1$ or fasting glucose $>7.0 \mathrm{mmol} / 1$, there was definitive history of diabetes, or hypoglycemic agents were being taken.

Urine ACR ratio was reliably correlated with 24-h urine protein and the reference value was generally in the range of $0.10-0.20$.

First morning urine was completely drained and urine was collected from the second urination. The first urine time was recorded and used as reference for $24 \mathrm{~h}$ on the following day. All urine within $24 \mathrm{~h}$ was placed in a container and mixed evenly, then 100-200 $\mathrm{ml}$ was extracted. The protein content in the healthy urine was generally $40-80 \mathrm{mg}$. Beyond this range, the diagnosis of proteinuria was made.

Glomerular filtration rate (GFR): The amount of filtered liquid generated from the two kidneys of normal adults was $80-120 \mathrm{ml} / \mathrm{min}$.

Other biochemical indicators were tested with the assistance of the clinical laboratory of Yantaishan Hospital (Shandong, China).

The APGAR score (8) included skin color, heart rate, reaction of flicking planta pedis or inserting nasal tube, muscle tension and breathing of the delivered newborn (Table I).

Statistical analysis. Data were presented as mean \pm standard error. The Pearson correlation analysis was performed to investigate associations between various indicators. In addition, multivariate and logistic regression analyses were carried out to identify the variables predictive of APGAR scores. $\mathrm{P}<0.05$ was consideted to indicate a statistically significant difference.

\section{Results}

General clinical parameters of the enrolled participants. A total of 6,758 pregnant women with combined gestational hypertension and proteinuria diagnosed at the Department of Obstetrics and Gynecology in Yantaishan Hospital from September, 2009 to June, 2011 were randomly selected for the study. Kidney function, blood pressure, history of gravidity and parity, embryo number and birth weight of the enrolled participants were determined. The average age of participants was $25.3 \pm 12.6$ years, with mean arterial pressure of $118.5 \pm 21.3 \mathrm{mmHg}$ and $24-\mathrm{h}$ urine protein content of $121.7 \pm 14.5 \mathrm{mg}$. According to the medical examination information of pregnant women, various indicators were recorded before and after pregnancy and statistical analysis was performed (Table II).

Pearson correlation analysis between perinatal outcomes and other factors. We recorded and statistically analyzed the APGAR scores of newborns delivered by the participants. According to a literature review, the indicators affecting APGAR score during pregnancy were screened as independent variables and a correlation analysis was performed. The 

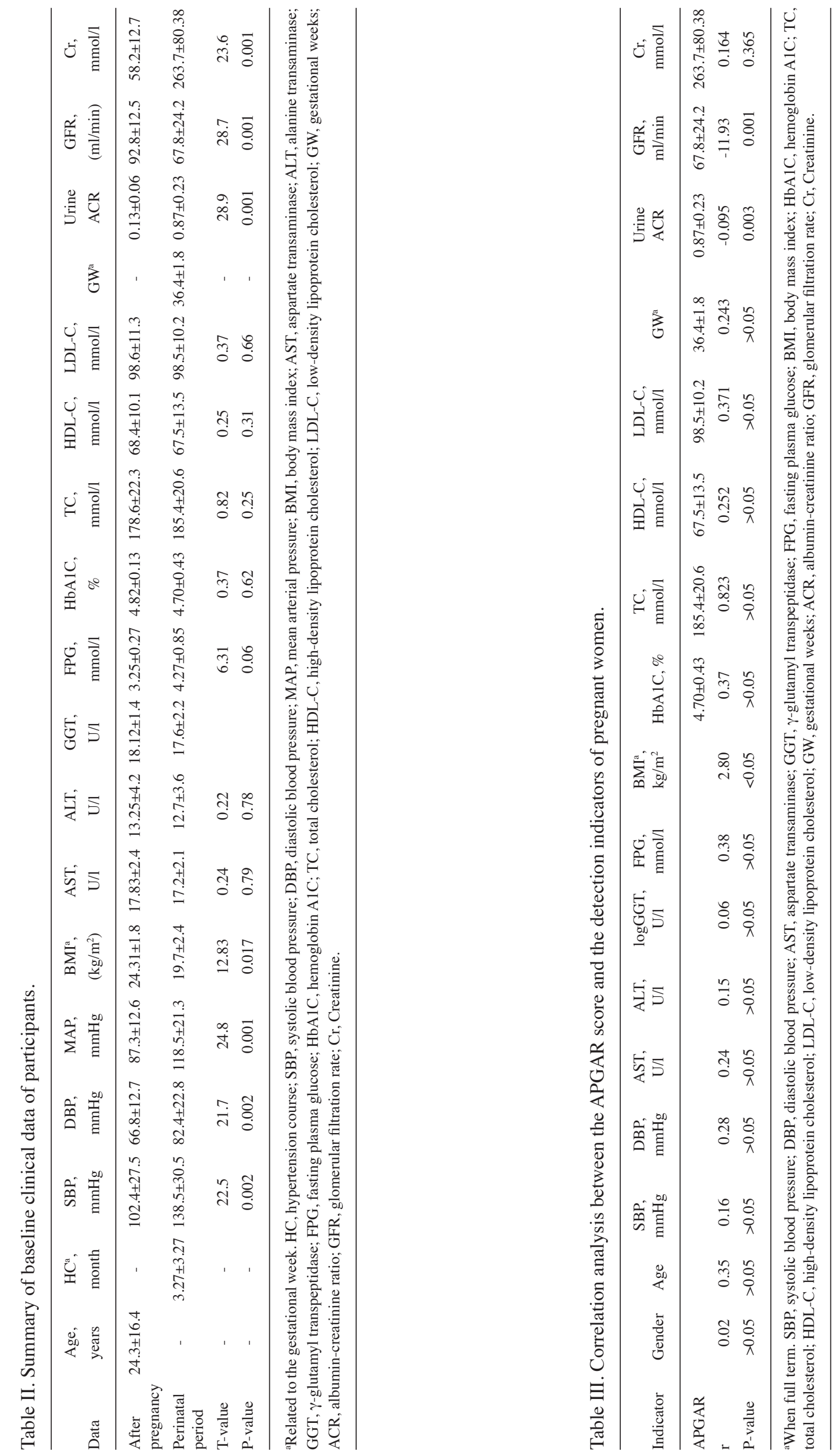
Table IV. Logistic regression analysis on the newborn APGAR score and influencing factors.

$(95 \% \mathrm{CI})$

\begin{tabular}{lccccccc} 
Variables & $\beta$ & $\mathrm{SE}$ & $\beta^{\prime}$ & $\mathrm{t}$ & P-value & Upper limit & Lower limit \\
\hline GFR & 0.581 & 0.10 & 0.642 & 0.652 & 0.362 & 0.39 & 0.78 \\
m-Alb/Cr & 0.243 & 0.01 & 0.352 & 0.431 & 0.001 & 0.21 & 0.80 \\
BMI & 0.768 & 0.08 & 0.871 & 0.981 & 0.325 & 0.61 & 0.92
\end{tabular}

CI, confidence interval; GFR, glomerular filtration rate; BMI, body mass index; $\beta$, regression coefficient; SE, standard error.

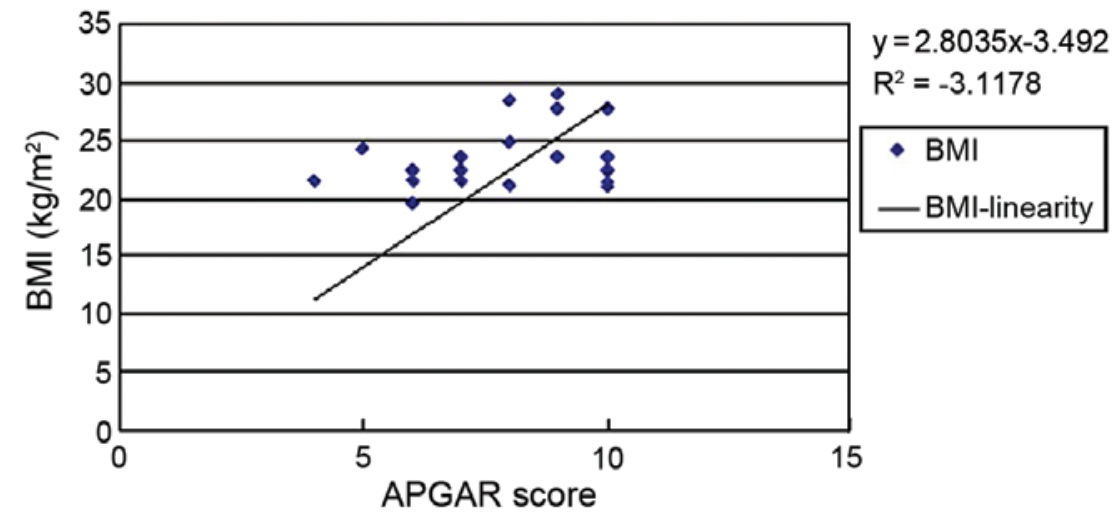

Figure 1. Pearson correlation analysis scatter diagram for body mass index (BMI) and APGAR score y=2.8035x-3.492.

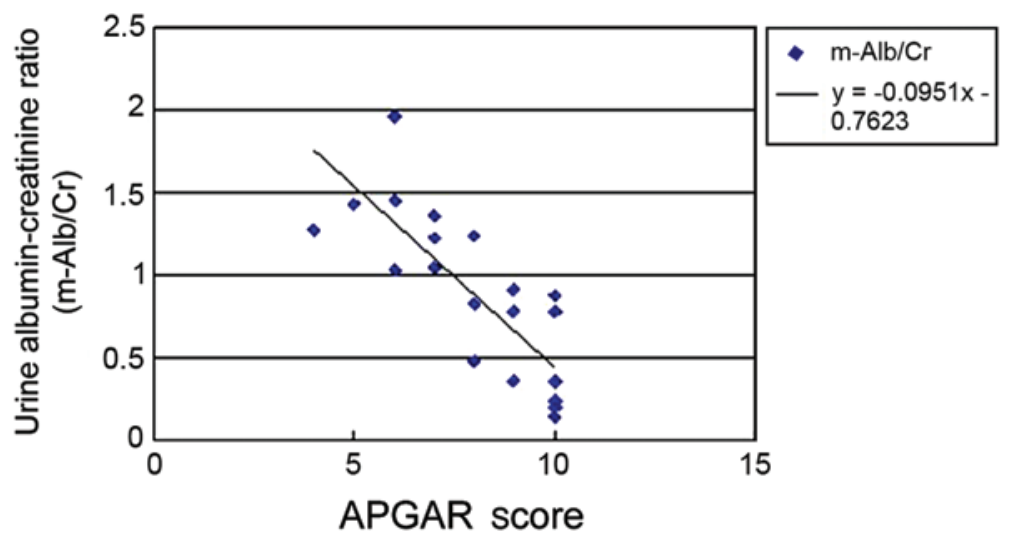

Figure 2. Pearson correlation analysis scatter diagram for $\mathrm{m}-\mathrm{Alb} / \mathrm{Cr}$ and APGAR score $\mathrm{y}=-0.0951 \mathrm{x}-0.7623$.

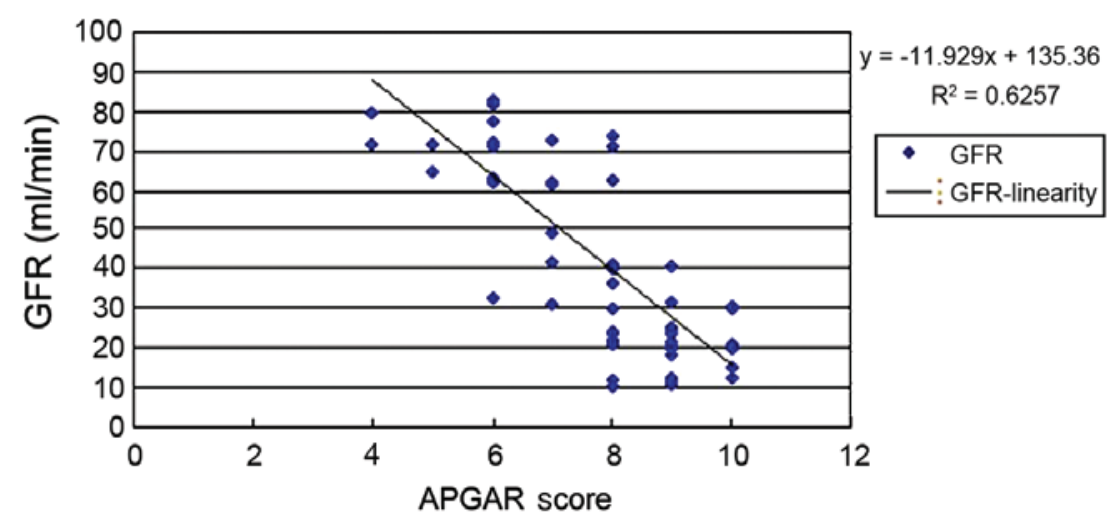

Figure 3. Pearson correlation analysis scatter diagram for glomerular filtration rate (GFR) and APGAR score $\mathrm{y}=-11.929 \mathrm{x}+135.36$. 
results showed that BMI (Fig. 1), urinary ACR (Fig. 2) and GFR (Fig. 3) of pregnant women were related to the APGAR score and the differences were statistically significant $(\mathrm{P}<0.05$; Table III).

Multivariate and logistic regression analysis on perinatal outcomes and other factors. A logistic regression analysis on all risk factors was performed, and we found that urine ACR and the APGAR score were positively correlated and the correlation coefficient was -0.0951 . The difference was statistically significant $(\mathrm{P}=0.001$; Table IV).

\section{Discussion}

Proteinuria during pregnancy severely affects the health of the fetus and mother (2). In normal delivery or after termination of pregnancy, these changes may gradually be restored. Under the physiological environment of pregnancy, previous kidney diseases may become worse and severe cases may cause new kidney damage such as acute renal failure (5,7,9-11). From the classification of pregnancy-related kidney diseases, kidney diseases caused by pregnancy do not include pre-eclampsia and eclampsia-induced renal lesions, or diseases occurring before pregnancy such as preeclampsia-associated focal segmental glomerulosclerosis. Some kidney diseases before pregnancy such as focal segmental glomerulosclerosis, IgA nephropathy, membranous nephropathy, reflux nephropathy and even lupus nephritis may be triggered by pregnancy. In addition, hemolytic uremic syndrome and renal cortical necrosis after pregnancy is not uncommon (12-16). In the present study, the average age of enrolled women was $25.3 \pm 12.6$ years, with mean arterial pressure of $118.5 \pm 21.3 \mathrm{mmHg}$ and $24 \mathrm{~h}$ urine protein content of $121.7 \pm 14.5 \mathrm{mg}$. None of the pregnant women had significant hypertension or proteinuria prior to pregnancy.

We determined the indicators associated with proteinuria during pregnancy from the relevant literature and statistically analyzed them in the study participants. The results showed that the BMI, urine ACR and GFR of pregnant woman were associated with the APGAR score and the differences were statistically significant $(\mathrm{P}<0.05)$. The Pearson correlation analysis diagram for BMI and APGAR score was $y=2.8035 x-3.492$, but in multivariate analysis $(\mathrm{P}>0.05)$. During pregnancy, change in weight is highly related to gestational week and fetal weight, although we found there was a linear relationship between weight and the APGAR score. However, there were many confounding factors in the linear relationship, and after the exclusion of these factors, no significant correlation between BMI and APGAR score was found ( $P>0.05)$.

We also analyzed the relationship between GFR and the APGAR score and found that $y=-11.929 x+135.36(P>0.05)$. According to previous literature, an increase in GFR mainly occured because of increased space between glomerular podocytes, caused by renal lesions. Among women with hypertensive proteinuria, the hypertension-induced glomerular perfusion pressure was significantly increased because membrane filtration permeability was increased. In addition, HCG, h-PL, steroid hormones and estrogen during pregnancy may have increased GFR. Decreased negatively charged salivary proteins on the filtration membrane attenuated the repulsion effect on albumin which was also negatively charged, and proteinuria occurred. However, it was not considered the influencing factor on perinatal outcome.

The determination of urine protein-creatinine ratio can effectively reflect the maternal 24-h urine protein content and excludes the result bias caused by poor compliance and many other factors. In the present study, we found a linear relationship between maternal ACR and APGAR score, $y=-0.0951 x-0.7623$ $(\mathrm{P}<0.05)$, suggesting that proteinuria may affect the fetus in utero, thereby affecting perinatal outcomes. Previous studies showed that if early proteinuria during pregnancy was $>300 \mathrm{mg} / 24 \mathrm{~h}$, careful clinical attention should be given. These patients were frequently combined with gestational hypertension, leading to reduced fetal survival rate, growth retardation and premature birth $(13,15,16-18)$. Proteinuria during pregnancy can manifest as mild proteinuria, combined proteinuria and hypertension, severe pre-eclampsia, severe eclampsia and other serious obstetric complications that potentially cause hypoxia, acidosis, bleeding, microcirculation, multiple organ failure and other serious complications (19-22).

In summary, there is an important correlation between perinatal maternal ACR and perinatal outcome. The increase in random urine ACR may predict postpartum outcome. Intervention in early pregnancy or before pregnancy has important clinical significance in reducing adverse complications for infants and mothers such as hypertension in pregnancy and improving the outcome of pregnancy.

\section{References}

1. Puri CP and Garfield RE: Changes in hormone levels and gap junctions in the rat uterus during pregnancy and parturition. Biol Reprod 27: 967-975, 1982.

2. Duvekot JJ, Cheriex EC, Pieters FA, Menheere PP and Peeters LH: Early pregnancy changes in hemodynamics and volume homeostasis are consecutive adjustments triggered by a primary fall in systemic vascular tone. Am J Obstet Gynecol 169: 1382-1392, 1993.

3. Holobotovskyy V, Chong YS, Burchell J, He B, Phillips M, Leader L, Murphy TV, Sandow SL, McKitrick DJ, Charles AK, et al: Regulator of $\mathrm{G}$ protein signaling 5 is a determinant of gestational hypertension and preeclampsia. Sci Trans1 Med 7: 290ra88, 2015.

4. Yi WY and Lin XJ: Clinical analysis of 43 cases of nephrotic syndrome with pregnancy induced hypertension. Chin Birth Health Hered 6: 76-78, 2007 (In Chinese).

5. Fraser A, Nelson SM, Macdonald-Wallis C, Sattar N and Lawlor DA: Hypertensive disorders of pregnancy and cardiometabolic health in adolescent offspring. Hypertension 62: 614-620, 2013.

6. Thoulass JC, Robertson L, Denadai L, Black C, Crilly M, Iversen L, Scott NW and Hannaford PC: Hypertensive disorders of pregnancy and adult offspring cardiometabolic outcomes: A systematic review of the literature and meta-analysis. J Epidemiol Community Health 70: 414-422, 2016.

7. Chen TK, Gelber AC, Witter FR, Petri M and Fine DM: Renal biopsy in the management of lupus nephritis during pregnancy. Lupus 24: 147-154, 2015.

8. McCarthy EA, Carins TA, Hannigan Y, Bardien N, Shub A and Walker SP: Effectiveness and safety of 1 vs $4 \mathrm{~h}$ blood pressure profile with clinical and laboratory assessment for the exclusion of gestational hypertension and pre-eclampsia: A retrospective study in a university affiliated maternity hospital. BMJ Open 5: e009492, 2015

9. Pahwa MB, Seth S and Khosla A: Significance of urine protein/ creatinine ratio in pregnancy-induced hypertension. Clin Chimacta 382: 145-147, 2007

10. Van Lente F and Suit P: Assessment of renal function by serum creatinine and creatinine clearance: Glomerular filtration rate estimated by four procedures. Clin Chem 35: 2326-2330, 1989. 
11. Milnerowicz-Nabzdyk E, Zimmer M, Tlolka J, Michniewicz J, Pomorski M and Wiatrowski A: Umbilical cord morphology in pregnancies complicated by IUGR in cases of tobacco smoking and pregnancy-induced hypertension. Neuro Endocrinol Lett 31: 842-847, 2010

12. Dong XD and Peng J: Pregnancy combined with chronic glomerulonephritis. Chin Obstetric Emergency 2: 96-98, 2012 (In Chinese).

13. Zhou JF, Wang XY, Shangguan XJ, Gao ZM, Zhang SM, Xiao WQ and Chen CG: Increased oxidative stress in women with pregnancy-induced hypertension. Biomed Environ Sci 18 419-426, 2005 .

14. Egerman RS, Witlin AG, Friedman SA and Sibai BM: Thrombotic thrombocytopenic purpura and hemolytic uremic syndrome in pregnancy: Review of 11 cases. Am J Obstet Gynecol 175: 950-956, 1996.

15. Li YQ, Wu YY, Gong X, Wu XF, Liu HY and Qiao FY: The study about the relationship between the kidney injury in gestational hypertension and the pregnancy outcomes. Chin Birth Health Hered 3: 71-72, 2013 (In Chinese).

16. Morikawa M, Yamada T, Yamada T, Shimada S, Koyama T, Cho K and Minakami H: Pregnancy-induced antithrombin deficiency. J Perinat Med 38: 379-385, 2010.
17. Sugisaki T: Mechanism by which proteinuria exacerbates kidney diseases. Nippon Naika Gakkai Zasshi 90: 1292-1298, 2001 (In Japanese)

18. Thornton CE, Makris A, Ogle RF, Tooher JM and Hennessy A: Role of proteinuria in defining pre-eclampsia: Clinical outcomes for women and babies. Clin Exp Pharmacol Physiol 37: 466-470, 2010.

19. Bramham K, Briley AL, Seed P, Poston L, Shennan AH and Chappell LC: Adverse maternal and perinatal outcomes in women with previous preeclampsia: A prospective study. Am J Obstet Gynecol 204: 512.e1-512.e9, 2011.

20. Craici IM, Wagner SJ, Weissgerber TL, Grande JP and Garovic VD: Advances in the pathophysiology of pre-eclampsia and related podocyte injury. Kidney Int 86: 275-285, 2014.

21. Ahmed A and Ramma W: Unravelling the theories of pre-eclampsia: Are the protective pathways the new paradigm? Br J Pharmacol 172: 1574-1586, 2015.

22. Law KP,Han TL, Tong C and Baker PN: Mass spectrometry-based proteomics for pre-eclampsia and preterm birth. Int J Mol Sci 16: 10952-10985, 2015. 